\title{
ANALYZING RELATIONSHIPS AMONG SUCCESS VARIABLES OF CONSTRUCTION PARTNERING USING STRUCTURAL EQUATION MODELING: A CASE STUDY OF TAIWAN'S CONSTRUCTION INDUSTRY
}

\author{
Wei Tong Chen ${ }^{1}$, Tung-Tsan Chen ${ }^{2}$, Chun Sheng Lü ${ }^{3}$, Shu-Shun Liu ${ }^{4}$ \\ ${ }^{1,4}$ Dept. of Construction Engineering, National Yunlin University of Science \& Technology, Yunlin 640, Taiwan \\ ${ }^{2}$ Dept. of Civil Engineering and Engineering Management, National Quemoy University, Kinmen 892, Taiwan \\ ${ }^{3}$ Graduate School of Engineering Science \& Technology, National Yunlin University of Science \& Technology, \\ Yunlin 640, Taiwan \\ E-mails: ${ }^{1}$ chenwt@yuntech.edu.tw (corresponding author); ${ }^{2}$ tungtsan@nqu.edu.tw; \\ ${ }^{3}$ lu9116213@yahoo.com.tw; ${ }^{4}$ ssliu@yuntech.edu.tw
}

Received 10 Aug. 2010; accepted 13 Dec. 2011

\begin{abstract}
This study explored the success variables (SVs) in construction partnering and the relationships among the SVs using structural equation modeling (SEM). Research results show that four successful factors (collaborative team culture, long-term quality perspective, consistent objectives, and resource sharing) have a significant influence on the success of construction partnering. Of the four factors, collaborative team culture and consistent objectives have the highest correlation. Collaborative team culture and long-term quality perspective have the lowest correlation. Additionally, good cultural fit has the most influence on characterizing collaborative team culture, commitment to continuous improvement has the highest influence in characterizing long-term quality perspective, clear understanding has the highest influence in characterizing consistent objectives, and availability of resource has the highest influence in characterizing resource sharing. The proposed SEM framework provides information which enables the users to control individual SV by considering their relationships with other SVs.
\end{abstract}

Keywords: success variable, construction partnering, construction industry, factor analysis, structural equation modeling.

\section{Introduction}

Success in construction projects is dependent on the effective organization of multiple, specialized teams, each of which brings its own ability, experience, knowledge and skill towards completing the joint project, but which also bring their own objectives, goals and management styles, which may not be entirely complimentary. Failure to tightly coordinate communication between these teams can result in schedule delays, cost overruns and poor final results, exposing project participants to potential legal and financial repercussions (Thompson, Sanders 1998; Cheng, Li 2002). Over the past few decades, increased competition, expectations, globalization and regulation have transformed the construction industry, and firms have responded by seeking alternative management methods to allow them to rapidly and flexibly respond to construction problems and manage risk.

Numerous studies have yielded several definitions of partnering, such as W. T. Chen and T.-T. Chen (2007), Bennett and Jayes (1998), Crowley and Karim (1995) and Yeung et al. (2007a). Nyström (2005) even proposed a new method to define the concept of partnering in a flexible and structured way. He concluded that there are two necessary components in partnering - trust and mutual understanding - and other components can be added to form a specific variant of partnering. However, the definition developed by the Construction Industry Institute (CII) in the United States is the most widely cited one. CII defines partnering as "a long-term commitment between two or more organizations is important for achieving specific business objectives by maximizing the resources of each participant. Accordingly, it is necessary to replace traditional relationships with a shared culture without regard to organizational boundaries. Such a new relationship is based on trust, dedication to common goals, and an understanding of individual expectations and values".

The fundamental principles of partnering, namely trust, commitment, communication, respect, and equality, include appropriate consideration of the interests of all parties at every level (CII 1991; Cowan et al. 1992; Uher 1999; Li et al. 2000), and aim to build "trust" among the parties involved in a contract. Such trust helps avoid problems with the project that recently have tended to lead to litigation (Moore et al. 1992; Wong et al. 2005). Partnering is a way to quickly, efficiently and inexpensively achieve these goals (Wilson et al. 1995). Additional advantages of partnering include reduced risks, cooperative problem solving, increased competitive advantage, increased asset security, the opening of new markets, and the enhancement of productivity (Chan et al. 2004; W. T. Chen, T.-T. Chen 2007; Yeung et al. 2007b). In Taiwan's construction in- 
dustry, a constant lack of trust and verification of information has characterized the working relationship between owners, designers, contractors and materials providers. Owners continually seek the lowest cost contractors (Chen et al. 2010). In response to perceived exploitation by owners, contractors (professionals) gradually become less loyal and less trustworthy. Therefore, the practice of construction partnering between owners and contractors is steadily growing.

Researchers and practitioners have proposed various success factors to facilitate construction partnering. Chan et al. (2006) identified 10 critical success factors (CSFs) of partnering projects among the private, public and infrastructure sectors in six cited projects in Hong Kong. The top three CSFs are "mutual trust amongst the project participants", "early implementation of partnering process" and "commitment to win-win attitude". "Regular monitoring of partnering process" was the least important CSF amongst the six partnering projects. They concluded that the level of mutual trust and the level of commitment to a win-win attitude are the most critical factors to partnering success. Cheng and Li (2002) used two surveys (a simple rating method and the analytic hierarchy process) to produce empirical evidence for highlighting the relationships between the construction CSFs and individual partnering process stages, namely: formation, application, and completion/reactivation. The study reaffirms that there are critical common factors affecting the whole partnering process and various CSFs influencing particular process stages. Specifically, the four critical common factors are: top management support, open communication, effective coordination, and mutual trust. Cheng et al. (2000) developed a framework to identify the CSFs for construction parties implementing partnering arrangements. The CSFs identified in the framework are effective communication, conflict resolution, adequate resources, management support, mutual trust, long-term commitment, coordination, and creativity. The framework highlights the influence of contextual characteristics and management skills on partnering success. However, incentivization scheme has recently been found to be another factor of partnering success. Chan et al. (2008) analyzes the rationale behind the successful development of partnering culture based on a case study of the infrastructure sector of Hong Kong. According to their results, they recommended that partnering together with target cost contracts, such as incentive agreement, greatly assists in the achievement of construction excellence and can provide a workable model for enhancing overall project performance in electrical and mechanical projects.

Using the Delphi survey technique, Yeung et al. (2007b) developed a model to objectively measure the performance of partnering projects in Hong Kong based on a consolidated Key Performance Indicators' conceptual framework. A composite Partnering Performance Index for Hong Kong's partnering projects can provide an all around assessment of partnering performance. The index can be used to measure, evaluate and improve the performance of partnering projects to strive for construction excellence. Additionally, Yeung et al. (2008) established quantitative indicators (QIs) and quantitative ranges (QRs) for each KPI's for Hong Kong's construction projects. The identified QIs and QRs could be used to evaluate objectively different partnering projects on a common basis and then help to set a benchmark for measuring the performance level of partnering projects. QIs and QRs can be applied to measure, evaluate and improve the existing performance of their partnering projects to strive for construction excellence. In summary, previous research in this field has identified various success factors of construction partnering. However, the relationships among these success factors of construction partnering remain unclear.

Defining a construction partner as an owner or professional participant in a jointly-managed construction project, this type of partnership was present in Taiwan's construction industry over 20 years ago, but was obscured by poorly defined contracts. With Taiwan's economic development, globalization, and privatization of public enterprises, over the past ten or so years, public and private construction partnerships have come to be defined as cooperation between construction management partners, with owners and contractors emerging as the primary advocates for partnership. However, the state has no clear policy for implementing such partnerships, thus making it difficult to accurately count the number of projects implemented under such partnerships. Jointly-managed construction projects began over 20 years ago in Taiwan with a model promoted by the private sector, and has developed up through the most recent decade as a publicprivate construction industry partnership defined in the spirit of cooperation on jointly-managed construction projects. The aim of this study is to explore the SVs in construction partnering in Taiwan and the relationships among these identified SVs.

\section{Questionnaire development and distribution}

\subsection{Questionnaire development}

This empirical study obtained raw data using a questionnaire survey. The questionnaire used a Likert-type scale from 1 (extremely unimportant) to 5 (extremely important). The original questionnaire included 22 structural questions representing 22 nominated SVs in construction partnership. Respondents contributed their opinions on the importance of construction partnering. Reliability testing was conducted to examine measurement accuracy and also to ensure that characteristics and variables were accurately measured. The measurements were combined with the forecast number of characteristics to represent the correct measurements.

As seen in Table 1, 22 nominated SVs were collected based on the framework for developing construction partnerships proposed by Li et al. (2001), the behavioral aspects of construction partnerships by Cheung et al. (2003), insights on co-operation in construction projects from Cheung et al. (2003) and Li et al. (2001), and insights on project management, project objectives and success factors (Chan et al. 2004; Belout, Gauvreau 2004; Atkinson 1999; Chua et al. 1999). 
Table 1. The 22 nominated SVs in construction partnership

\begin{tabular}{lcc}
\hline \multicolumn{1}{c}{ Success Variables } & \multicolumn{2}{c}{ Survey Result } \\
\cline { 2 - 3 } & Means & Ranking \\
\hline SV1 Mutual trust & 4.32 & 6 \\
SV2 Effective communication & 4.63 & 1 \\
SV3 Commitment from senior & 4.25 & \\
$\quad$ management & & 8 \\
SV4 Clear understanding & 4.24 & 9 \\
SV5 Acting consistent with objectives & 4.37 & 3 \\
\hline SV6 Dedicated team & 4.03 & 17 \\
SV7 Flexibility to change & 4.07 & 14 \\
SV8 Commitment to quality & 4.33 & 5 \\
SV9 Commitment to continuous & 4.16 & \\
$\quad$ improvement & & 12 \\
SV10 Long-term perspective & 3.92 & 18 \\
\hline SV11 Total cost perspective & 4.20 & 10 \\
SV12 Formation at design stage & 4.05 & 16 \\
SV13 Good cultural fit & 3.80 & 19 \\
SV14 Company wide acceptance & 4.08 & 13 \\
SV15 Technical expertise & 4.39 & 2 \\
\hline SV16 Financial security & 4.29 & 7 \\
\hline SV17 Questioning attitudes & 4.35 & 4 \\
\hline SV18 Availability of resources & 4.06 & 15 \\
\hline SV19 Equal power/empowerment & 4.18 & 11 \\
SV20 Contract administration & 3.31 & \\
$\quad$ capabilities & & 20 \\
SV21 Ability to obtain business & 3.15 & 22 \\
SV22 Adapt owner changes & 3.22 & 21 \\
\hline
\end{tabular}

The study questionnaire was validated through a pilot test and distributed to forty-two experienced construction industry professionals who were asked to complete the questionnaire and comment on its readability, comprehensiveness and precision. The pilot test (questionnaire) was distributed to forty-two experienced construction industry professionals including 12 project owners, 10 practitioners of design firms, 10 contractors, and 10 academic professionals. Table 2 shows the background of the 42 professionals including years of working experience, current position and specialties. Highly equipped with popularity and recognition in the construction industry, the 42 professionals were requested to complete the questionnaire and comment on its readability, comprehensiveness and precision. Thirty-four completed questionnaires were collected and Cronbach's $\alpha$ determined for each factor, returning a reliability value of 0.904 , which indicates a high degree of reliability (Gay 1996). Referring to Table 1 , there is a huge gap $(0.49 / 5.0=$ $12.89 \%$ ) between 19th-ranked SV13 and 20th-ranked SV20 in terms of variable average value. Therefore, it was decided that any variable with an average value below 3.8 would be deleted. The corrected scale contained 19 SVs, reduced from 22 SVs. Three variables which were deleted include Contract administration capabilities (3.31), Ability to obtain business (3.15) and Adapt owner changes (3.22).

Table 2. Background of the 42 professionals

\begin{tabular}{|c|c|c|c|}
\hline Roles & $\begin{array}{l}\text { Yrs. of Working } \\
\text { Experience }\end{array}$ & Position & Working Attributes and Specialties \\
\hline 1 & 2 & 3 & 4 \\
\hline Project owner 01 & 35 & GM & Business planning, corporation management \\
\hline 02 & 21 & GM & Corporation management, business coordination \\
\hline 03 & 35 & GM & Corporation management \\
\hline 04 & 28 & Deputy GM & Business development, corporation management \\
\hline 05 & 30 & $\mathrm{AM}$ & Land development, business coordination \\
\hline 06 & 27 & AM & Construction and Management \\
\hline 07 & 20 & VM & Marketing and sales, business coordination \\
\hline 08 & 32 & Manager & Project management \\
\hline 09 & 28 & President & Corporation management \\
\hline 10 & 16 & VM & Marketing and sales, business coordination \\
\hline 11 & 31 & President & Business planning, corporation management \\
\hline 12 & 28 & President & Corporation management, business coordination \\
\hline Designer 01 & 26 & Deputy GM & Design, business coordination \\
\hline 02 & 30 & GM & Planning and design, business coordination \\
\hline 03 & 20 & Architect & Planning and design, supervision \\
\hline 04 & 33 & Architect & Planning and design \\
\hline 05 & 30 & Architect & Planning and design \\
\hline 06 & 35 & Architect & Planning and design \\
\hline 07 & 32 & Architect & Design review, business coordination \\
\hline 08 & 28 & Architect & Planning and design, supervision \\
\hline 09 & 30 & Manager & Design review, business coordination \\
\hline 10 & 34 & PE (structural engineering) & Structural design, supervision \\
\hline Contractor 01 & 29 & GM & Corporation and construction management \\
\hline 02 & 22 & Deputy GM & Project and construction management \\
\hline 03 & 25 & GM & Corporation and construction management \\
\hline 04 & 21 & Manager & Project and construction management \\
\hline 05 & 25 & PE (civil engineering) & Project and construction management \\
\hline 06 & 20 & Manager & Project and construction management \\
\hline 07 & 10 & PE (structural engineering) & Project and construction management \\
\hline
\end{tabular}


End of Table 2

\begin{tabular}{r|c|c|l}
\hline \multicolumn{1}{r|}{} & 2 & 3 & 4 \\
\hline 08 & 17 & Manager & Project and construction management \\
\hline 09 & 20 & Vice Manager & Project and construction management \\
\hline Academic expert 01 & 31 & Manager & Project and construction management \\
\hline 02 & 26 & AP & Transportation Engineering \\
\hline 03 & 18 & AP \& Dept. head & Transportation engineering \\
\hline 04 & 12 & AP \& Director & Architectural engineering \\
\hline 05 & 18 & AP \& Dept. Chair & Architectural engineering \\
\hline 06 & 15 & APofessor \& Dept. Chair & Civil engineering management \\
\hline 07 & 8 & Assistant Professor & Civil engineering management \\
\hline 08 & 20 & Professor & Construction engineering management \\
\hline 09 & 16 & AP & Construction engineering management \\
\hline 10 & 25 & Professor & Construction engineering management
\end{tabular}

Note: GM: General Manager; VM: Vice Manager; AM: Assistant Manager; PE: Profession Engineer; AP: Associate Professor

\subsection{Questionnaire distribution}

The survey was distributed to construction industry practitioners in Taiwan. The research subjects were drawn based on the three considerations: (1) different project attributes (high-tech/non-high-tech) and scales (large/ small) may result in different aspects for evaluation; (2) most high-tech construction projects in Taiwan are large-scale; (3) most non-high tech projects could be classified as large-scale and small-scale projects. Consequently, respondents were found in high-tech large construction projects (HLCP), non-high-tech large construction projects (NLCP), and non-high-tech small construction projects (NSCP). High-tech construction projects are large projects requiring highly-interfaced integration, such as the Taiwan High Speed Rail project. Non-high-tech construction projects do not require highinterface integration (e.g., roadway construction). Three hundred and thirty questionnaires were distributed via mail, e-mail, fax, telephone and personal delivery, with 221 retrieved (67\% response rate). As seen in Table 3, 50 responses came from HLCPs, 125 from NLCPs, and 46 from NSCPs. Broken down by profession, the sample included 39 (17.6\%) government employees, 32 (14.5\%) project owners. 63 (28.5) design professionals and 87 (39.4\%) construction firms. The respondent group was made up of highly-experienced professionals, with nearly $75 \%$ having over 5 years of experience in the industry. Although construction professionals are not necessarily knowledgeable in partnering practices, they still are more conversant on the subject than those with less construction experience.

Table 3. Analysis of the sampling group

\begin{tabular}{lccccc}
\hline Sampling group & HLCP & NLCP & NSCP & Total & $\%$ \\
\hline Government & 3 & 22 & 14 & 39 & 17.6 \\
employee & & & & & \\
Project owner & 14 & 16 & 2 & 32 & 14.5 \\
Design firm & 4 & 39 & 20 & 63 & 28.5 \\
Construction firm & 29 & 48 & 10 & 87 & 39.4 \\
Total & 50 & 125 & 46 & 221 & 100.00 \\
\hline
\end{tabular}

Note: HLCP stands for hi-tech large construction projects; NLCP stands for non-hi-tech large construction projects; NSCP stands for non-hi-tech small construction projects

\subsection{Correlation analysis of SV}

Based on the survey results, correlation analysis using Pearson's correlation coefficient was conducted and discussed as follows. Pearson's correlation coefficient is a statistical tool used to determine the degree and direction of relatedness between two variables. Possible values of the correlation coefficient range from -1.00 to +1.00 , and the closer the number is to an absolute value of 1.00 , the greater the degree of relationship. Table 4 shows the correlation among all examined variables executed by SPSS.

The Bartlett test of sphericity for the survey is 1613.353 , and the associated significance level is 0.000 , indicating that the population correlation matrix is not an identity matrix (Norusis 2001). The Kaiser-Meyer-Olkin (KMO) measure of sampling adequacy is 0.900 , which is significantly greater than 0.5 and thus is considered highly acceptable. The results of tests show the sample data is appropriate for FA. Referring to Table 4, the relationships with high-correlation coefficients (greater than 0.5 ) were as follows: SV6 (dedicated team) with SV7 (flexibility to change), SV7 (flexibility to change) with SV18 (availability of resources), SV8 (commitment to quality) with SV9 (commitment to continuous improvement), SV9 (commitment to continuous improvement) with SV17 (questioning attitudes), SV12 (formation at design stage) with SV13 (good cultural fit), SV13 (good cultural fit) with SV14 (company wide acceptance), SV18 (availability of resources) with SV19 (equal power/empowerment).

The obtained correlation coefficients have certain implications. For example, the higher occurrence of "commitment to quality" implies a higher occurrence of "commitment to continuous improvement". The higher correlations among SVs (Table 4) also demonstrated that correlations among SVs are complicated and require further investigation. The implications provide limited information to users because the correlation coefficient indicates only a simple relationship between two variables. Users cannot gain a holistic perception of most key variables of project partnering. Therefore, correlation coefficient analysis alone in this case cannot provide an acceptable result for distinguishing the relationships among SVs of construction partnering. 
Table 4. Correlation matrix showing correlations among the SV for partnering

\begin{tabular}{|c|c|c|c|c|c|c|c|c|c|c|c|c|c|c|c|c|c|c|c|}
\hline SVs & SV1 & SV2 & SV3 & SV4 & SV5 & SV6 & SV7 & SV8 & SV9 & SV10 & SV11 & SV12 & SV13 & SV14 & SV15 & SV16 & SV17 & SV18 & SV19 \\
\hline SV1 & 1.000 & & & & & & & & & & & & & & & & & & \\
\hline SV2 & 0.183 & 1.000 & & & & & & & & & & & & & & & & & \\
\hline SV3 & 0.280 & 0.270 & 1.000 & & & & & & & & & & & & & & & & \\
\hline SV4 & 0.288 & 0.330 & 0.347 & 1.000 & & & & & & & & & & & & & & & \\
\hline SV5 & 0.317 & 0.311 & 0.255 & 0.460 & 1.000 & & & & & & & & & & & & & & \\
\hline SV6 & 0.339 & 0.229 & 0.198 & 0.426 & 0.410 & 1.000 & & & & & & & & & & & & & \\
\hline SV7 & 0.267 & 0.348 & 0.264 & 0.418 & 0.306 & 0.546 & 1.000 & & & & & & & & & & & & \\
\hline SV8 & 0.182 & 0.210 & 0.177 & 0.288 & 0.321 & 0.343 & 0.323 & 1.000 & & & & & & & & & & & \\
\hline SV9 & 0.139 & 0.214 & 0.274 & 0.371 & 0.345 & 0.375 & 0.402 & 0.720 & 1.000 & & & & & & & & & & \\
\hline SV10 & 0.300 & 0.263 & 0.210 & 0.420 & 0.331 & 0.423 & 0.412 & 0.437 & 0.499 & 1.000 & & & & & & & & & \\
\hline SV11 & 0.190 & 0.207 & 0.268 & 0.174 & 0.295 & 0.187 & 0.283 & 0.175 & 0.240 & 0.266 & 1.000 & & & & & & & & \\
\hline SV12 & 0.122 & 0.232 & 0.166 & 0.331 & 0.264 & 0.371 & 0.304 & 0.353 & 0.434 & 0.402 & 0.195 & 1.000 & & & & & & & \\
\hline SV13 & 0.300 & 0.190 & 0.224 & 0.422 & 0.330 & 0.489 & 0.473 & 0.332 & 0.391 & 0.499 & 0.165 & 0.576 & 1.000 & & & & & & \\
\hline SV14 & 0.191 & 0.185 & 0.202 & 0.354 & 0.372 & 0.456 & 0.423 & 0.225 & 0.345 & 0.386 & 0.254 & 0.474 & 0.564 & 1.000 & & & & & \\
\hline SV15 & 0.221 & 0.319 & 0.232 & 0.390 & 0.378 & 0.415 & 0.348 & 0.322 & 0.388 & 0.358 & 0.158 & 0.237 & 0.328 & 0.341 & 1.000 & & & & \\
\hline SV16 & 0.193 & 0.284 & 0.352 & 0.284 & 0.360 & 0.254 & 0.334 & 0.309 & 0.351 & 0.319 & 0.424 & 0.239 & 0.310 & 0.366 & 0.432 & 1.000 & & & \\
\hline SV17 & 0.197 & 0.261 & 0.255 & 0.450 & 0.459 & 0.395 & 0.390 & 0.477 & 0.522 & 0.471 & 0.254 & 0.293 & 0.416 & 0.302 & 0.459 & 0.458 & 1.000 & & \\
\hline SV18 & 0.318 & 0.279 & 0.304 & 0.362 & 0.300 & 0.390 & 0.512 & 0.310 & 0.360 & 0.414 & 0.398 & 0.267 & 0.386 & 0.457 & 0.314 & 0.367 & 0.445 & 1.000 & \\
\hline SV19 & 0.186 & 0.312 & 0.319 & 0.368 & 0.325 & 0.289 & 0.383 & 0.247 & 0.432 & 0.404 & 0.314 & 0.294 & 0.327 & 0.397 & 0.351 & 0.399 & 0.393 & 0.522 & 1.000 \\
\hline
\end{tabular}

Note: Kaiser-Meyer-Olkin $(\mathrm{KMO})$ measure of sampling adequacy $=0.900$; Bartlett test of sphericity $=1613.353$;

Degree of freedom $=171$; Significance $=0.000$

\subsection{Success variables extraction}

Factor analysis identifies clusters of related variables and can thus be used to generate a comprehensible framework (Norusis 2001) using a data matrix produced from individual cases or respondents. Factor analysis commonly uses principal component analysis which generates linear combinations of variables or factors to explain variance in the data. Since the goal of FA is inclusive clustering of initial variables, a variable load exceeding 0.5 (rounded) on the factor was considered acceptable variable and left unmodified.

Factor analysis was applied here to explore the underlying constructs of the 19 SVs for construction partnering using principal component analysis and varimax rotation. SPSS was used to automatically generate a matrix along with the FA. Via the rule of eigenvalue greater than one, the four-Factor solution was considered the most appropriate. Table 4 shows that the Cronbach's $\alpha$ values for all four SFs exceed 0.7 , which is the threshold of acceptability. Meanwhile, the cumulative criteria explanation value is $56.58 \%$, meaning that the four SFs can explain $56.58 \%$ of the variances in the SVs. Table 5 lists the SFs and their associated SVs. Every SF is named according to its associated SVs. Among the four extracted SFs, six of the SVs loaded on Collaborative team culture, three of the SVs loaded on Long-term quality perspective, five of the SVs loaded on Consistent objectives and five of the SVs loaded on Resource sharing. The four SFs were seen as the Latent variables ( $\eta i)$ for performing SEM.

Collaborative team culture refers to partnerships in which team members are free to challenge the assumptions of the others, thus making the group process transparent and encouraging individuals to question their own assumptions (Lewis 1990). Long-term quality perspectives indicate the willingness of the respective teams to continuously manage unanticipated problems (Bresnen, Marshall 2000). Teams which have a greater commitment to a project are less likely to exhibit opportunistic behavior, and are more likely to give priority to achieving long-term goals as opposed to short-term expedients (Mohr, Spekman 1994). Consistent objectives are the individual strategic goals of the respective project members which can converge to act in concert to achieve joint goals. This is critical in that ambiguous goals and poor coordination are the leading causes of partnership failure (Lynch 1990). However, when effectively managed, partnerships can raise competitiveness and expand operational capabilities, and provide a venue in which firms are incentivized to share technologies, experience, information, knowledge, and skills (CII 1991). 


\section{SEM framework for construction partnerships}

\subsection{SEM framework development}

SEM can describe the relationships among observed and latent variables. The data represented by observed variables can be directly measured, while those represented by latent variables cannot be directly observed, and must be expressed in frameworks that describe them in terms of observed variables. SEM implementation involves a measurement component and a structural component (Byrne 1994); the former specifies how latent variables are measured in terms of observed variables, while the latter expresses relationships among latent variables. Thus, using SEM, a latent theoretical structure can be represented by measured variables in a causal indicator framework, while simultaneously accounting for measurement errors, thus producing more accurate representations.

This study proceeded to develop and test the structural relationships between SVs of construction partnering using SEM. A basic framework was developed by incorporating the latent constructs with their corresponding measures into an initial SEM on the basis of theoretical expectations and past empirical findings. Framework improvements were performed over several iterations to arrive at a final framework specification by using a combination of modification indices (Hoyle 1995) and theoretical justifications until a final satisfactory framework was identified. Additionally, to ensure the appropriateness of factors of the identified attributes as construction partnering SVs, Cronbach's $\alpha$ reliability testing was applied. Cronbach's $\alpha$ values range from 0 to 1 . Values ranging from 0.6 to 0.7 are considered sufficient, and values above 0.7 are considered reliable (Sharma 1995).
The SEM framework, consisting of a measurement component and a structural component, was built using AMOS. The measurement component determines how well exogenous variables measure latent variable constructs, while the structural component models the relationships among latent variable constructs to explicitly model direct, indirect and correlative effects. Fig. 1 displays the format of the initial SEM framework with path coefficients. For each variable, Fig. 1 shows its influence on different variables and its connection to the SF. The rectangles in Fig. 1 indicate observed (or measured) variables. Unobserved latent variable constructs appear in ellipses. The arrows in the figure indicate the direction of hypothesized influence. For example, the influence of $\eta 2$ (long-term quality perspective) is presumed to be reflected in the observed measures of the variables: SV8 (commitment to quality), SV9 (commitment to continuous improvement) and SV17 (questioning attitudes) as depicted by the directional arrows. Error terms are included for each exogenous variable indicating a latent variable construct. For example, SV8 (commitment to quality) does not perfectly describe $\eta 2$ (long-term quality perspective), and so an error term is needed to represent the error of measurement. This error term, $\varepsilon 8$, is an unobserved entity consisting of the portion of measured value of SV8 (commitment to quality) that does not reflect the influence of $\eta 2$ (long-term quality perspective). According to Fig. 1 it is obvious that the degree of partnering success is determined by the three main influence SFs, and there are several courses of influence in each SF.

\subsection{SEM framework assessment}

From Table 5, all SFs in the initial SEM had Cronbach's $\alpha$ values higher than 0.7 , indicating sufficient internal

Table 5. Principal components analysis on success variables and reliability testing of initial SEM

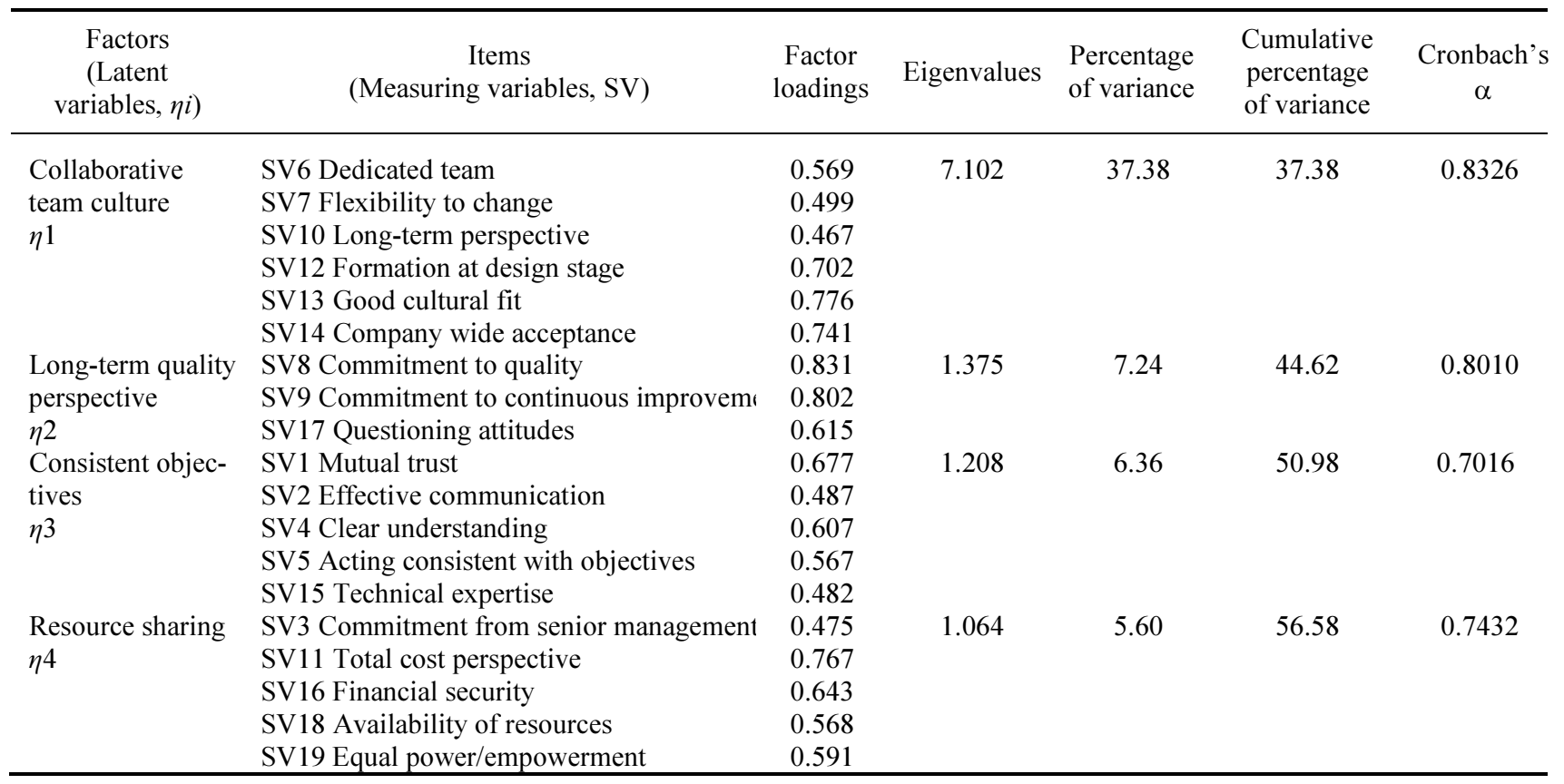

Note: $\eta i$ and SVi represent success factors on partnering, latent variables, and observable variables, respectively. 


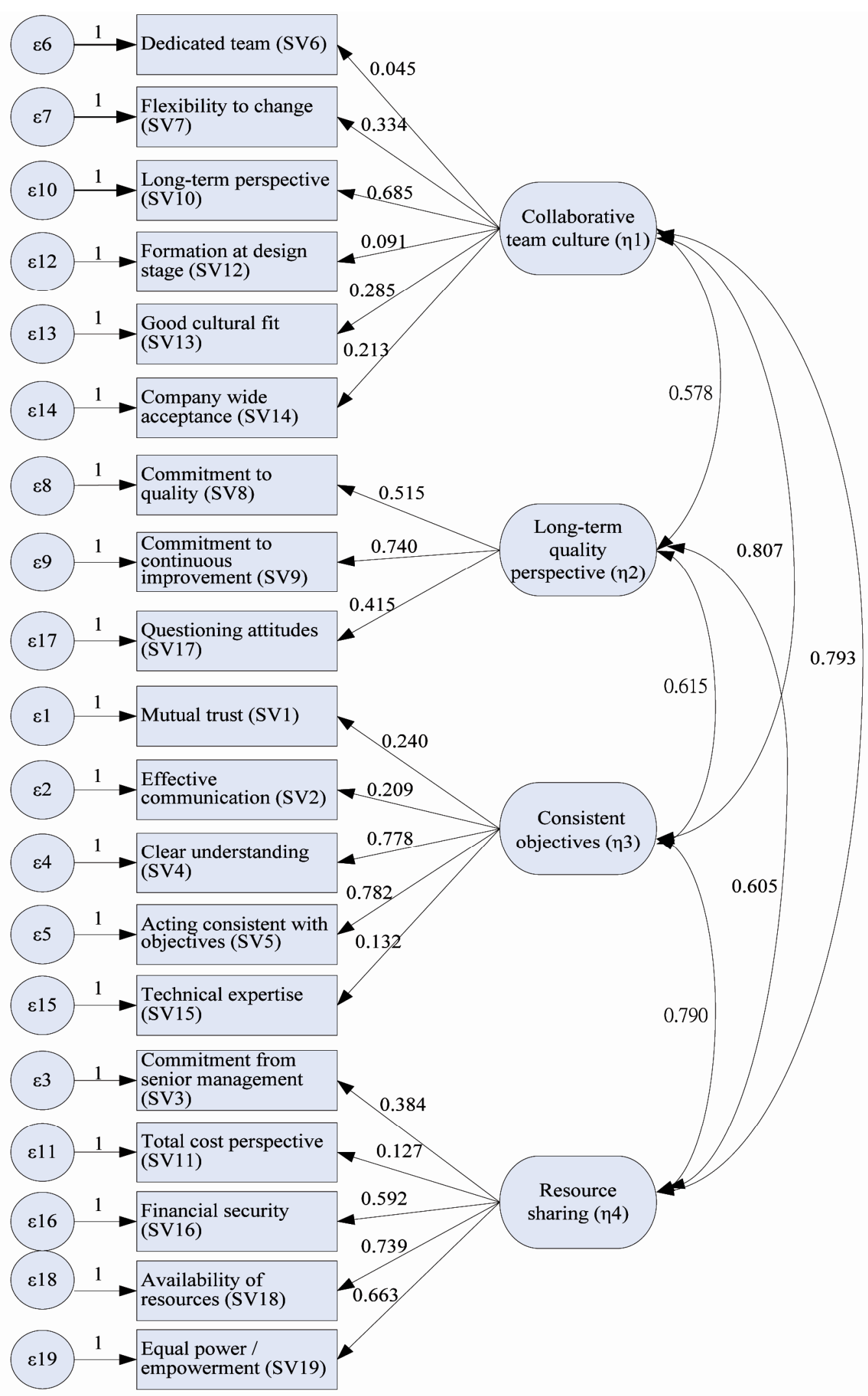

Fig. 1. Initial SEM framework with coefficients 
consistency of the initial SEM. The overall fitness of the initial SEM can be assessed by employing goodness of fit (GOF) indices. Several GOF indices are available to test the fitness of the SEM. If the GOF indices of the initial SEM do not reach the recommended levels, framework refinements are required to improve overall fitness.

In this study, framework refinements were performed by two methods. First, low correlation paths and associated variables were systematically eliminated (Sarkar et al. 1998). The interrelationship paths were then revised or covariance error paths were added between the variables or latent factors. Both methods were needed to refine the SEM framework with reference to the modification indices provided by the AMOS. After refinement, the framework with the best performance for both GOF and the theoretical expectations (Molenaar et al. 2000) was selected as the final SEM framework.

Table 6 summarizes all indices and the suggested levels of GOF for initial and final SEM frameworks. Two indices of the initial SEM framework, RMSEA $(=0.056)$ and Noelter CN value $(=150)$, fail to reach the recommended levels of GOF showing the need for the refinement of the initial SEM framework. After two runs of refinement, all GOF indices of the initial SEM framework reached the recommended levels, and are therefore seen as the final version of the SEM framework. Fig. 2 shows the final SEM framework with path coefficients.

\section{Results and discussion}

All the path coefficients for the measurement component of the SEM framework are nonzero with a $95 \%$ confidence level. Thus, the coefficients provide meaningful implications that significant influences exist from observed variables to latent variables. As stated before, SEM involves two procedures (a measurement component and a structural component) discussed as follows.

\subsection{Measurement component of developed SEM framework}

Fig. 2 shows how the factors by which the latent variable collaborative team culture is measured in the SEM framework: team dedication, flexible response to change, long-term perspective, formation at the design stage, good cultural fit and widespread acceptance. Good cultural fit had the strongest influence $(\lambda=0.724)$, followed by team dedication $(\lambda=0.701)$, flexible response to change $(\lambda=0.692)$, widespread acceptance $(\lambda=0.681)$, and long-term perspective $(\lambda=0.470)$, while formation at design stage was the least influential $(\lambda=0.397)$. Conflict had a small effect of the team spirit engendered by mutual trust, effective communication, full acknowledgement and respect. These positive aspects reduce conflicts and quarrels, and establish a better working environment for the project (Stipanowich 1997).

The SEM framework measures the latent variable of long-term quality perspective according to commitment to quality, commitment to continuous improvement, questioning attitude, long-term perspective and formation at the design stage. Commitment to continuous improvement was found to have the greatest influence on longterm quality perspective $(\lambda=0.918)$ followed by commitment to quality $(\lambda=0.785)$, questioning attitudes $(\lambda=0.321)$, and long-term perspective $(\lambda=0.279)$, while formation at the design stage had the least influence $(\lambda=0.229)$, most likely due to the increased versatility and complexity of the construction industry and the evolution of required skills and procedures. Increased demand among customers for better quality and durability has also raised the importance of commitment to longterm quality, which can only be ensured through mutual commitment to continuously improve the partnering arrangement (Brensen, Marshall 2000; Cheng et al. 2000).

The SEM framework measures the latent variable for consistent objectives by referring to clear understanding, acting consistently with objectives, technical expertise and questioning attitudes, with clear understanding exhibiting the greatest effect on consistent objectives

Table 6. Goodness of fit measurement of the SEM framework

\begin{tabular}{llcccc}
\hline \multirow{2}{*}{ Evaluation index } & \multicolumn{1}{c}{ GOF } & $\begin{array}{c}\text { Suggested } \\
\text { level }\end{array}$ & Initial SEM & $\begin{array}{c}\text { First revised } \\
\text { SEM }\end{array}$ & $\begin{array}{c}\text { Second revised } \\
\text { (Final) SEM }\end{array}$ \\
& & The least & 875.683 & 195.425 & 119.431 \\
& Pearson chi-square, $\chi^{2}$ & & 518 & 84 & 79 \\
& Degree of freedom, dof & $>0.05$ & 0.000 & 0.000 & 0.002 \\
& Probability, P & $<0.05$ & 0.036 & 0.033 & 0.022 \\
& RMR value & $<0.05$ & 0.056 & 0.078 & 0.048 \\
& RMSEA value & $>0.9$ & 0.811 & 0.897 & 0.936 \\
& GFI value & $>0.9$ & 0.747 & 0.861 & 0.915 \\
& NFI value & $>0.9$ & 0.879 & 0.915 & 0.969 \\
& IFI value & $>0.9$ & 0.877 & 0.914 & 0.969 \\
\hline Relative fit index & CFI value & $<3$ & 1.691 & 2.326 & 1.512 \\
& NCI value & $>0.5$ & 0.690 & 0.688 & 0.688 \\
& PNFI value & $>0.5$ & 0.810 & 0.731 & 0.729 \\
& PCFI value & $\geq 200$ & 150 & 132 & 205 \\
\hline Prosimonious fit index & Hoelter CN value & The least & 1029.683 & 276.425 & 201.431 \\
& Akaike AIC value & The least & 4.680 & 1.216 & 0.916 \\
\hline
\end{tabular}

Note: The first revised SEM deleted four SVs including mutual trust (SV1), effective communication (SV2); commitment from senior management (SV3), and total cost perspective (SV11) 


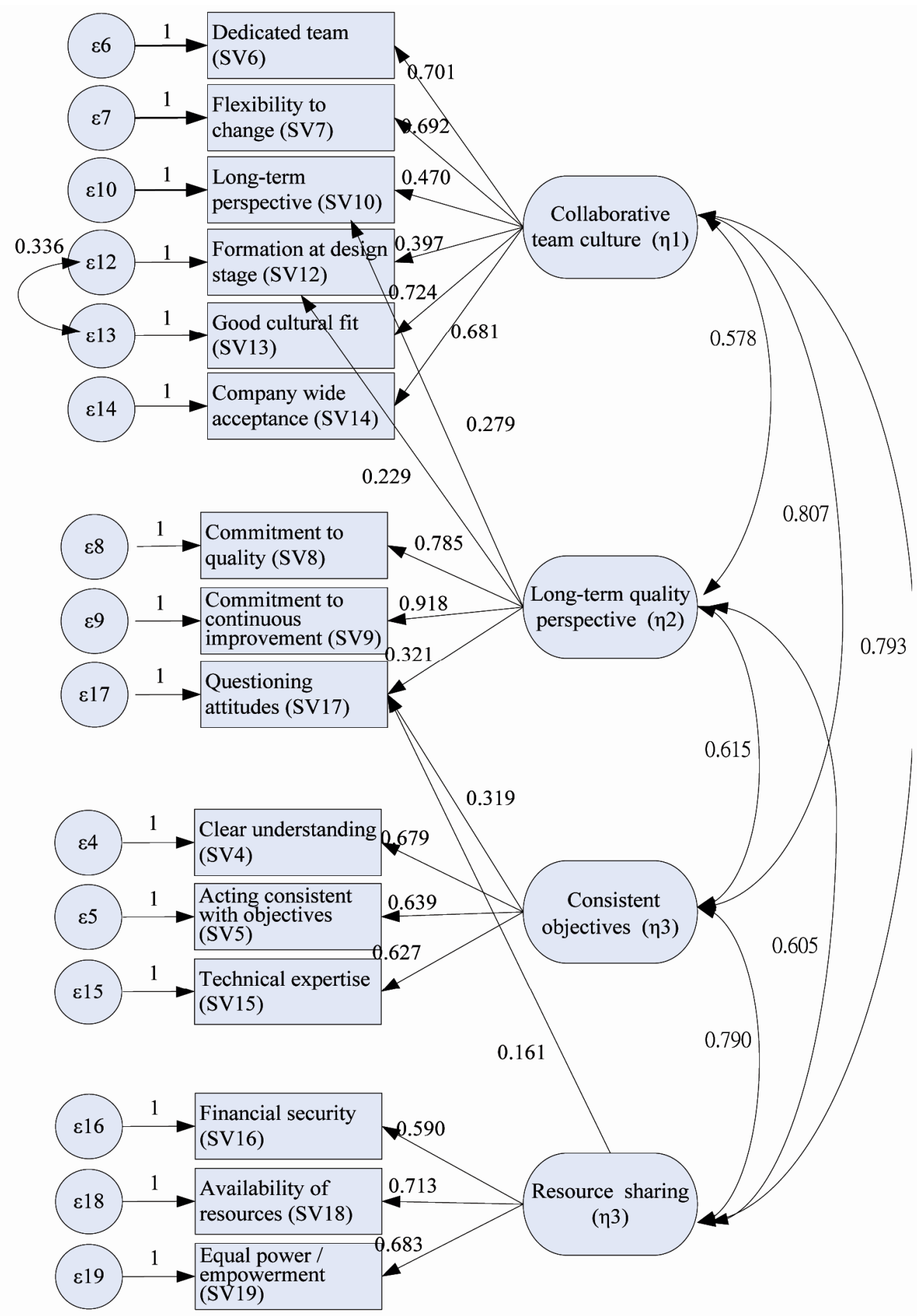

Fig. 2. Final SEM framework with coefficients

$(\lambda=0.679)$, followed by acting consistently with objectives $(\lambda=0.639)$ and technical expertise $(\lambda=0.627)$, while questioning attitudes exhibited the least influence $(\lambda=0.319)$. Collective objectives, actions and ideas form the basis for cooperation between partners and, aside from professional knowledge and effective communication, to achieve project objectives efficiently, partners need to have a clear understanding of the project and the team members' respective strengths (Black et al. 2000).

The SEM framework measures the resource sharing latent variable by reference to financial security, availabi- lity of resources, equal power/empowerment and questioning attitudes. Availability of resources had the strongest effect on resource sharing $(\lambda=0.713)$, followed by equal power/empowerment $(\lambda=0.683)$ and financial security $(\lambda=0.590)$, while questioning attitudes had the smallest effect $(\lambda=0.161)$. Failure to instill win-win attitudes among the project teams could disrupt the project flow, and reduce the effective use of resources including equipment, financing, staff, materials, and information (Ellison, Miller 1995; Brooke, Litwin 1997). 


\subsection{Structural component of developed SEM framework}

The initial research framework suggests the four latent variables (collaborative team culture, long-term quality perspective, consistent objectives, and resource sharing) are connected in a linear relationship, with the strongest correlation between collaborative team culture and consistent objectives $(\psi=0.807)$, followed by collaborative team culture and resource sharing $(\psi=0.793)$, consistent objectives and resource sharing $(\psi=0.790)$, long-term quality and consistent objectives $(\psi=0.615)$ and longterm quality perspective and consistent objectives $(\psi=$ 0.605 ), while the weakest correlation was between collaborative team culture and long-term quality perspective $(\psi=0.578)$. This implies that the four SFs all exert a considerable influence on the success of construction partnering, thus supporting the hypotheses presented above.

This paper examines the ability of the structural components of the four latent variables to fit the data sample. The correlations found among the four latent variables range between 0.578 and 0.807 , which suggests a high degree of relationships, according to Bryman and Cramer (1990). Additional discriminant validity testing also suggest a $95 \%$ probability for the four latent variables of partnering, showing them to be statistically independent (Jöreskog, Sörbom 2002).

Additionally, according to Fig. 2, there is no indirect influence from individual SV. Since these four SFs strongly affect one another, these four SFs and their framework applications must be deeply probed to achieve successful project results via partnering. Therefore, the SEM framework provides a meaningful map with path coefficients for describing and quantifying the influences of different variables on successful construction partnering. This kind of information cannot be provided by previous studies (Chan et al. 2006; Cheng, Li 2002; Cheng et al. 2000), and is useful for describing correlations among SVs of construction partnering. Users can control individual variables by considering their relationships with other variables.

\section{Conclusions and recommendations}

This study explored SVs of construction partnering. Factor analysis was used to identify 19 SVs which were classified into four SFs (collaborative team culture, long-term quality perspective, consistent objectives, and resource sharing). The SEM was then used to analyze the relationships among these identified SVs and SFs. The proposed SEM framework not only provides meaningful information that was not provided by previous studies, but also enables the users to control individual SV by considering their relationships with other SVs.

Research results show that four SFs have a significant influence on the success of construction partnering. Among the four SFs, collaborative team culture and consistent objectives have the highest correlation. Collaborative team culture and long-term quality perspective have the lowest correlation. Additionally, good cultural fit has the most influence in characterizing collaborative team culture, commitment to continuous improvement has the highest influence in characterizing long-term quality perspective, clear understanding has the highest influence in characterizing consistent objectives, and availability of resources has the highest influence in characterizing resource sharing. These four SFs and their framework application must be deeply probed to achieve successful project results via partnering. This type of constructive information can facilitate construction partnering among project participants. Participants can manage construction partnering by considering the size of the coefficient, examining the individual intention for construction partnering and determining the relationship between those and other factors.

The study is only concerned with the construction partnering in Taiwan. Further investigation in different countries/areas is necessary due to the localized nature of the construction industry. Additionally, utilizing case studies in partnership to extend the research findings would be beneficial since the findings could be implemented and incorporated in today's construction projects to explore how the SVs are important for the construction projects. Future research should use multi-train confirmatory factor analysis to investigate partnerships in different populations, and explore whether the proposed measurement scales can be applied to the attributes of special projects such as Design-Build and BOT.

\section{Acknowledgments}

The authors would like to thank the organizations and practitioners for participating in the interview and questionnaire surveys. Special thanks also go to anonymous reviewers of the paper.

\section{References}

Atkinson, R. 1999. Project management: cost, time and quality, two best guesses and a phenomenon, its time to accept other success criteria, International Journal of Project Management 17(6): 337-342. http://dx.doi.org/10.1016/S0263-7863(98)00069-6

Belout, A.; Gauvreau, C. 2004. Factors influencing project success: the impact of human resource management, International Journal of Project Management 22(1): 1-11.

Bennett, J.; Jayes, S. 1998. The seven pillars of partnering: a guide to second generation partnering. Thomas Telford, UK. 96 p. http://dx.doi.org/10.1680/tspopagtsgp. 26902

Black, C.; Akintoye, A.; Fitegerald, E. 2000. An analysis of success factors and benefits of partnering in construction, International Journal of Project Management 18(6): 423434. http://dx.doi.org/10.1016/S0263-7863(99)00046-0

Bresnen, M.; Marshall, N. 2000. Motivation, commitment and the use of incentives in partnerships and alliances, Construction Management and Economics 18(5): 587-598. http://dx.doi.org/10.1080/014461900407392

Brooke, K. L.; Litwin, G. H. 1997. Mobilizing the partnering process, Journal of Management in Engineering ASCE 13(4): 42-48. http://dx.doi.org/10.1061/(ASCE)0742597X(1997)13:4(42)

Bryman, A.; Cramer, D. 1990. Quantitative data analysis for social scientists. New York: Routledge. 290 p. 
Byrne, B. M. 1994. Structural Equation Modeling with EQS and EQS/Windows: Basic concepts, applications and programming. Sage, Thousand Oaks, CA. 304 p.

Chan, A. P. C.; Chan, D. W. M.; Chiang, Y. H.; Tang, B. S.; Chan, E. H. W.; Ho, K. S. K. 2004. Exploring critical success factors for partnering in construction projects, Journal of Construction Engineering and Management ASCE 130(2): 188-198. http://dx.doi.org/10.1061/(ASCE)07339364(2004)130:2(188)

Chan, A. P. C.; Chan, D. W. M.; Fan, L. C. N.; Lam, P. T. I.; Yeung, J. F. Y. 2006. Partnering for construction excellence - a reality or myth?, Building and Environment 41(12): 1924-1933. http://dx.doi.org/10.1016/j.buildenv.2005.06.026

Chan, A. P. C.; Chan, D. W. M.; Fan, L. C. N.; Lam, P. T. I.; Yeung, J. F. Y. 2008. Achieving partnering success through an incentive agreement: lessons learned from an underground railway extension project in Hong Kong, Journal of Management in Engineering ASCE 24(3): 128-137. http://dx.doi.org/10.1061/(ASCE)0742-597X (2008)24:3(128)

Chen, W. T.; Chen, T.-T. 2007. Critical success factors for construction partnering in Taiwan, International Journal of Project Management 25(5): 475-484.

http://dx.doi.org/10.1016/j.ijproman.2006.12.003

Chen, W. T.; Liao, S. L.; Lu, C. S.; Mortis, L. 2010. Evaluating satisfaction with PCM services for school construction: a case study of primary school projects, International Journal of Project Management 28(3): 296-310.

http://dx.doi.org/10.1016/j.ijproman.2009.06.003

Cheng, E. W. L.; Li, H. 2002. Construction partnering process and associated critical success factors: quantitative investigation, Journal of Management in Engineering ASCE 18(4): 194-202. http://dx.doi.org/10.1061/(ASCE)0742597X(2002)18:4(194)

Cheng, E. W. L.; Li, H.; Love, P. E. D. 2000. Establishment of critical success factors for construction partnering, Journal of Management in Engineering ASCE 16(2): 84-92. http://dx.doi.org/10.1061/(ASCE)0742-597X(2000) 16:2(84)

Cheung, S.-O.; Ng, T. S. T.; Wong, S.-P.; Suen, H. C. H. 2003. Behavioral aspects in construction partnering, International Journal of Project Management 21(5): 333-343. http://dx.doi.org/10.1016/S0263-7863(02)00052-2

Chua, D. K. H.; Kog, Y. C.; Loh, B. K. 1999. Critical success factors for different project objectives, Journal of Construction Engineering and Management ASCE 125(3): 142-150. http://dx.doi.org/10.1061/(ASCE)0733-9364 (1999)125:3(142)

Construction Industry Institute (CII). 1991. In search of partnering excellence. Special Publication No.17-1, Rep., Partnering Task Force of CII, Austin, T.X.

Cowan, C.; Gray, C.; Larson, E. 1992. Project partnering, Project Management Journal 22(4): 5-12.

Crowley, L. G.; Karim, A. Md. 1995. Conceptual model of partnering, Journal of Management in Engineering ASCE 11(5): 33-39. http://dx.doi.org/10.1061/(ASCE)0742597X(1995)11:5(33)

Ellison, S. D.; Miller, D. W. 1995. Beyond ADR: working toward synergistic strategic partnership, Journal of Management in Engineering ASCE 11(6): 44-54. http://dx.doi.org/10.1061/(ASCE)0742-597X(1995) $11: 6(44)$
Gay, L. R. 1996. Educational research: competencies for analysis and application. Merrill Prentice-Hall, Englewood Cliffs, N.J. 624 p.

Hoyle, R. H. 1995. The structural equation modeling approach: basic concepts and fundamental issues, in R. H. Hoyle (Ed.). Structural Equation Modeling: concepts, issues and applications, Sage Publications, Thousand Oaks, CA, 115.

Jöreskog, K. G.; Sörbom, D. 2002. LISREL 8: Structural Equation Modeling with the SIMPLIS command language. Scientific Software International, Chicago, I.L. 226 p.

Lewis, J. D. 1990. Partnerships for profit: structuring and managing strategic alliances. New York: The Free Press. $352 \mathrm{p}$.

Li, H.; Cheng, E. W. L.; Love, P. E. D. 2000. Partnering research in construction, Engineering, Construction and Architectural Management 7(1): 76-92.

Li, H.; Cheng, E. W. L.; Love, P. E. D.; Irani, Z. 2001. Cooperative benchmarking: a tool for partnering excellence in construction, International Journal of Project Management 19(3): 171-179. http://dx.doi.org/10.1016/S02637863(99)00033-2

Lynch, R. P. 1990. Building alliances to penetrate European markets, Journal of Business Strategy 11(2): 4-8. http://dx.doi.org/10.1108/eb039354

Mohr, J.; Spekman, R. 1994. Characteristics of partnering success: partnering attributes, communication behavior, and conflict resolution techniques, Strategic Management Journal 15(2): 135-152. http://dx.doi.org/10.1002/smj.4250150205

Molenaar, K.; Washington, S.; Diekmann, J. 2000. Structural equation model of construction contract dispute potential, Journal of Construction Engineering and Management ASCE 126(4): 268-277. http://dx.doi.org/10.1061/ (ASCE) 0733-9364(2000)126:4(268)

Moore, C.; Mosley, D.; Slagle, M. 1992. Partnering guidelines for win-win project management, Project Management Journal 22(1): 18-21.

Norusis, M. J. 2001. SPSS 10.0 guide to data analysis. Englewood Cliffs: Prentice Hall, N.J. 577 p.

Nyström, J. 2005. The definition of partnering as a Wittgenstein family-resemblance concept, Construction Management and Economics 23(5): 473-481. http://dx.doi.org/10.1080/01446190500040026

Sarkar, Mb.; Aulakh, P. S.; Cavusgil, S. T. 1998. The strategic role of relational bonding in interorganizational collaborations: an empirical study of the global construction industry, Journal of International Management 4(2): 85-107. http://dx.doi.org/10.1016/S1075-4253(98)00009-X

Sharma, S. 1995. Applied multivariate techniques. New York: Wiley.

Stipanowich, T. J. 1997. At the cutting edge: conflict avoidance and resolution in the US construction industry, Construction Management and Economics 15(6): 505-512. http://dx.doi.org/10.1080/014461997372700

Thompson, P. J.; Sanders, S. R. 1998. Partnering continuum, Journal of Management in Engineering ASCE 14(5): 7378. http://dx.doi.org/10.1061/(ASCE)0742-597X(1998) $14: 5(73)$

Uher, E. T. 1999. Partnering performance in Australia, Journal of Construction Procurement 5(2): 163-176.

Yeung, J. F. Y.; Chan, A. P. C.; Chan, D. W. M. 2007a. The definition of alliancing in construction as a Wittgenstein 
family - resemblance concept, International Journal of Project Management 25(3): 219-231.

http://dx.doi.org/10.1016/j.ijproman.2006.10.003

Yeung, J. F. Y.; Chan, A. P. C.; Chan, D. W. M.; Li, L. K. 2007b. Development of a partnering performance index (PPI) for construction projects in Hong Kong: a Delphi study, Construction Management and Economics 25(12): 1219-1237.

http://dx.doi.org/10.1080/01446190701598673

Yeung, J. F. Y.; Chan, A. P. C.; Chan, D. W. M. 2008. Establishing quantitative indicators for measuring the partnering performance of construction projects in Hong Kong, Construction Management and Economics 26(3): 277301. http://dx.doi.org/10.1080/01446190701793688
Wilson, R. A.; Songer, A. D.; Diekmann, J. 1995. Partnering: more than a workshop, a catalyst for change, Journal of Management in Engineering ASCE 11(5): 40-45. http://dx.doi.org/10.1061/(ASCE)0742-597X(1995) $11: 5(40)$

Wong, P. S. P; Cheung, S. O.; Ho, P. K. M. 2005. Contractor as trust initiator in construction partnering - prisoner's dilemma perspective, Journal of Construction Engineering and Management ASCE 131(10): 1045-1053. http://dx.doi.org/10.1061/(ASCE)0733-9364(2005)131: 10(1045)

Wei Tong CHEN. Doctor, Professor and Chairman. Dept. of Construction Engineering, National Yunlin University of Science and Technology. His major research interests include property management, scheduling and planning, performance evaluation, and value management.

Tung-Tsan CHEN. Doctor, Associate Professor. Dept. of Civil Engineering and Engineering Management, National Quemoy University. His major research interests include property management, scheduling and planning, project management.

Chun Sheng LU. Doctor, School of Engineering Science and Technology, National Yunlin University of Science and Technology. His main research interests include construction safety and public projects management. Mr. Lu was the division chief of Public Works Department, Chia-yi City Government, Taiwan.

Shu-Shun LIU. Doctor, Associate Professor, Dept. of Construction Engineering, National Yunlin University of Science and Technology. His major research interests include property management, optimization applications on construction management, scheduling and planning, and construction E-Business. 